\title{
PAIN IN THE OCCIPUT AND BACK OF NECK. STRONO RETRACTION OF 'THE HEAD. GLIOMA OF THE RIGHT TEMPORO-SPHENOMDL LOBE. NO DISEASE OF CEREBELLUM.
}

BY THOMAB BUZZARD, M.D., F.R.O.P.

Physician to the National Haspilal for the Paralysed and Epiloptio.

Tre patient was a gentleman aged twenty-seven. In 1873, as I am informed by his medical attendant, he complained of what he called "giddiness" or "nerrous attacks." He subsequently spent several months in North America, engaged in sporting. In 1877 his symptoms were nearly the same as in 1873 , and a physician who saw him regarded these and the former attacks as those of petit mal. He never lost consciousness. During last autumn he spent the season in successful grouse shooting. A week before his death he hunted on one day from ten to six o'clock. During the last two months of his life he complained of severe pain over the occiput and back of the neck, extending upwards on the right side of the head to the forehead and sometimes down the neck. The pain generally came on during the night, and disappeared after breakfast. He was sometimes free from pain for several days together. There was accasionally a little sickness. In the paroxysms of pain the head was drawn back during the last fow weeks of his life, and he complained of hemiopia. There was very slight facial paralysis of the left side.

Autopsy. - There was nothing abnormal in the appearance of the cerebral surface on opening the skull. When the brain was removed and turmed upside down, it was noted that the sulci of the inferior surface of the right temporo-sphenoidal lobe were effaced. Palpation of this lobe was accompanied by a sense of fluctuation, in striking contrast with the corresponding lobe of the left side, which presented the ordinary resistance of healthy brain. A vertical section through the right temporo-sphenoidal lobe showed that the grey matter of the cortex had disappeared, the exposed walls of the section presenting a flesh colour. The structure was, in parts, of a consis- 
tence somewhat more dense than that of healthy medullary matter which, however, it a good deal resembled in apperrance. At the depth of rather less than en inch the knife passed into a cyst-like cavity containing about two drachms of straw-coloured fluid, and large enough to hold two or three walnuts. The walls of the cavity were very smooth, and consisted of the same flesh-coloured substance as had been previously cut through. Several small hremorrhages were observed in the walls of the section. The abnormal structure or tumour merged quite insensibly into the surrounding brain substance, which was more or less softened throughout the whole of the right temporo-sphenoidal lobe, and some distance into the occipital lobe, as well as, though to a less extent, into the lower part of the convolutions bordering the fissure of Rolando.

The corebellum presented no signs of disease in any portion of its structure, nor was there any appearance of flattening of its upper surface. Under the microscope the tumour presented the characters of soft glioma tending to myxoma, numerous protoplasmic cells, with a few much larger ones, containing many nuclei, and bearing a general resemblance to mucus globules.

The patient was only seen by me shortly before his death, when he was in a state of coma, which was sometimes profound, whilst at other times he could stand, talk, and swallow liquids, although with great difficulty. The coma was partly due to a dose of morphia, which had been given for the relief of severe pain. I'he head was retracted, so that the occiput was nearly touching the cervical portion of the spinal colunn, the eyes were upturned and divergent, there was slight facial paralysis of the left side. He would keep his right hand to his forehead, and when asked if he was suffering pain in the head, would signify that this was so.

I learned that for upwards of two months past he had been subject to daily attacks, lasting many hours, of severe pain abont the back of the head and neck, accompanied occasionally, but not often, by romiting. In these attacks the head was drawn back, I was informed, in the way which I have described. Impairment of sight had been complained of, and there had apparently been hemiopia. An ophthalmoscopic examination had been proposed, but not made.

Incomplete as is the case, it seems an important one to place on record, because of the very striking symptom, retraction of the head.

Dr. Hughlings-Jackson has recorded examples of what he calls " cerebellar rigidity (part of which is retraction of the head), in cuses of cerebellar tumour. In some of these there were, voL. IV. 
besides, paroxysms like those of surgical tetanns. Similar observations have been made by Dr. Stephen Mackenzie. In the ' Lancet,' January 24, 1880, Dr. Hughlings-Jackson writes: "I have only once seen seizures like tetanus in a case of lecal cerebral disense, and in thet case they occurred during the last hours of life-during dying." .In the paper referred to he records a case of retraction of the head with tumour of the cerebellum. Of course retraction of the head is known to occur from other pathological changes, as cerebro-spinal meningitis for example, but for purposes of localisation cases of tumour supply the best evidence, though, unfortunately, from their size this evidence is not often very definite.

It is remarkable that a person suffering from so extensive and grave an intra-cranial lesion should have been able to enjoy a long day's bunting within a week of his death. 